International Journal of Engineering \& Technology, 7 (4) (2018) $2477-2480$
International Journal of Engineering \& Technology
SPC
Website: www.sciencepubco.com/index.php/IJET
doi: $10.14419 /$ ijet.v7it.13414
Research paper

\title{
Doctor appointment application: a user experience experiment
}

\author{
Firas Omar * \\ Software Engineering Department,Zarqa University, Jordan \\ *Corresponding author E-mail: firasomar@gmail.com
}

\begin{abstract}
Designing an application with elevated usability is the aim of the study. The more usable, more positive user experience we are achieving. The medical field is currently experiencing low UX applications and interfaces. The study will strive to address the healthcare systems in Jordan.

While taking the user into our consideration and giving what he/she might find usable and enjoyable a high priority, only by such approach we will succeed and achieve a positive user experience.
\end{abstract}

Keywords: Usability; User Experience; Health Care; E-Business.

\section{Introduction}

With the development witnessed by the world in the field of technology in most of the technological areas and the importance of the medical sector within our life, it became important to create a system to support the patients in such huge development.

The success of any computerised system falls under how Usable and user friendly it is. This will in its turn, lead to a better or poorer user experience.

\section{Background}

\subsection{Usability}

According to Woldu (2014), the term usability was firstly introduced in the early 1980's in order to replace the term user friendly. The first formal definition of usability was proposed by Nielsen, 2012 who is called as a founder of usability discipline. Nielsen stated a definition of usability as "the ability to be Used by humans easily and effectively".

As a result, a variety of many different usability definitions have been proposed. For example the international standards organization has defined usability as "The capability of the software or a product to be well understood, learned, in an attractive way to the user, while used under specified conditions." (ISO 9241-11) In ISO, usability has been defined in terms of measures for ease of use of products or systems.

Simply, we can give a straightforward definition of usability as how far can something be possibly used.

Usability measures and focuses on the quality of a user's experience within the interaction process with a product or system. From the user's point of view, usability is about how a system or a product performs what is meant to do precisely and correctly in order to address the user's requirements.
Once again and according to the usability professionals association (UPA), a definition was issued which focuses more on the development process of a product. In addition, they issued a definition of usability as "an approach to product development that incorporates direct user feedback throughout the development cycle in order to reduce costs and create products and tools that meet user needs". (Dumas \& Redish 1999, P. 97-261)

According to the usability expert Jacob Nielsen (1994), he defined usability as "quality of users experience during interaction with a system and includes four major characteristic for usability Such as effectiveness, efficiency, satisfaction and Learnability"

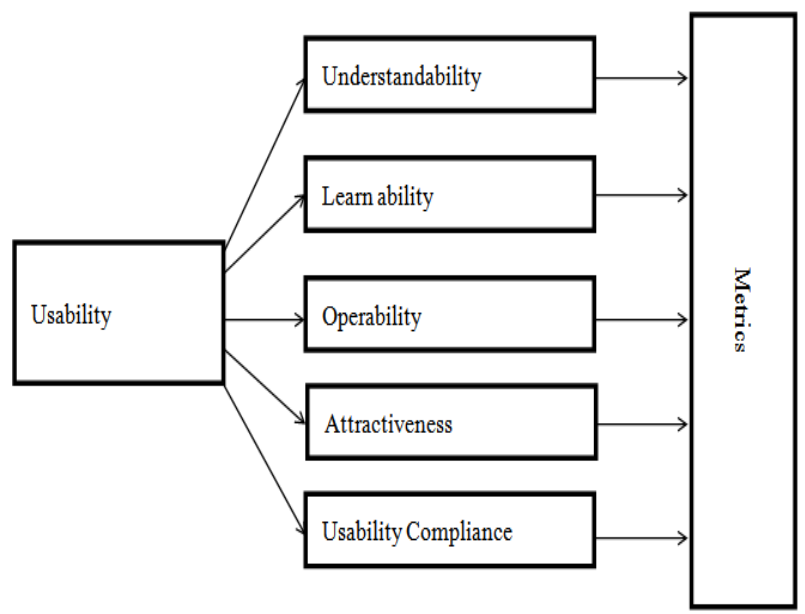

Fig. 1: Nielson Major Characteristic for Usability.

\subsection{Effectiveness}

Effectiveness conveys how completely and precisely the goal of users achieved as a result of using the system. Effectiveness determines how productive user can be with the system and it can also be pronounced as the speed in which users can accomplish the tasks in which they used the system or the product for. 
Effectiveness can be determined by looking at whether the user's goals were met successfully and correctly. Effectiveness focuses primarily with how quickly a task can be completed and considers how well the work is done. (Woldu, 2014)

\subsection{Efficiency}

According to Nielsen (1994), "Efficiency usually refers to the level of performance when the user interacting with a system". ISO 9241 defines efficiency as the amount of resources consumed in a task and how quickly users can complete their task.

At present, high level of efficiency is highly required by each user in order to be more productive in way that the system will support users swiftly to accomplish the task(s) they came for and help them to easily recover from any potential errors.

Efficiency is usually measured by completion time or action required to perform a task.

\subsection{Satisfaction}

Satisfaction is defined by how enjoyable the system is from the user point of view (Nielsen Norman Group 2012).

Satisfaction is concerned about the user feelings and opinions of the product or system. Satisfaction is a personal response from users about their feelings while interaction with the system.

\subsection{Learnability}

Learnability is the extent to which something can be adequately learned. Learnability is the most necessary usability attributes as it is crucial to most of the systems or products as they need needs to be learned as easily as possible.

Learnability is a part of effectiveness and reflects how quickly new users can learn to operate the system and quickly perform a task procedures. In addition, users tends to enjoy using systems that complete their desired goals in a short period of time instead of spending loads of time in trying to accomplish one single task. It is also important to keep an eye on how much of time to be spent on the process of learning something.

\section{User experience}

The corner stone of the usability planning process is the understanding of the user behavior besides their expectations along with what are they trying to accomplish. User experience (UX) I defined as the process of the interaction which takes place between the user and the system(s).Additionally, the emotions of the user and how does he feel towards the system takes a major role as well. (Morville, 2011)

Generally, users feeling user when they interact with the system for first time is like if they have done something wrong but after all they think it's not their fault the site doesn't work the way they expect but they still feel bad anyway (Woldu, 2014) "If you intend to drive people away from your site it's hard to imagine a more effective approach than making them feel stupid when they use it" (Jesse James Garrett 2011. User-Cantered design for the Web. P. 23-25). A good user experience is where a user archives their goals and satisfied with the process (Burton \& Taylor, 2004). User experience (UX) goal is to create a website which is easy to use, pleasing and valuable because mostly user are facing the site alone and no manual in-struction to read in advance or training to help guide them through the site they only use their personal experience. (Waldu, 2014).

According to Morville (2003), the success of website depends on what impact will fall on the user. "Does this website give me value? Is it easy to use? Is it pleasant to use? "(Morville Peter 2003. User experience Design P.21). the mentioned questions are a sample of what might come across the users mind within the interaction process with web site along with the first impression of whether they are about to become a regular user or not.
The process of designing a successful website must take into considerations both to desires and limitations and most importantly it must understand of user needs. This promotes to the understanding of the user's expectations within each step of the designed path throughout the whole designing process. This methodology will achieve a successful website.

Peter Morville deployed the seven usability concepts in a visual form, which was called later on the user experience honeycomb. The shape describes the elements of the overall users experience and how they would interact with each other to help to design a better site. The honeycomb helps to see the Web site from the user's point of view.

The elements on the honeycomb ensure that all different aspects are applied in to a right order with correct relations to one another. They also clarify the use of different terms on the user experience but they don't define what user experience is, just brings up the issues they should be considered while designing the Web.

The core for user experience is ensuring that users find value in what provided to them so in order to meet that information must be valuable, usable, useful, findable and credible and accessible. Each element is described as follows.

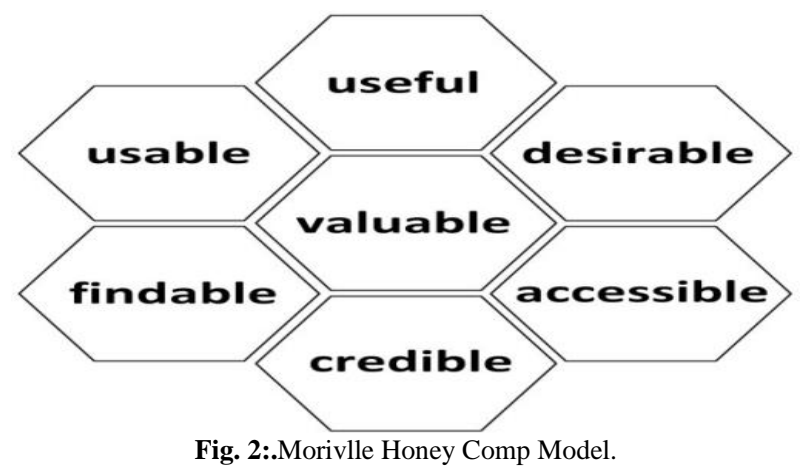

Flowing is an explanation for each component of the shape above:

\subsection{Valuable}

Value is a cornerstone of a good user experience. Sites must deliver value to users by designing the system features in a way that they support user needs. System that does not add a value and meet user needs does not provide a significant user experience.

\subsection{Usable}

Usable is about ease of use a highly usable system enables the user to achieve their goals with a minimum error. Usability is a functionality of the system that enables users to feel that they are able to use it without too much effort. (Morville, 2011)

\subsection{Useful}

User experience starts with a first impression while interacting with a system. Users need to gets most out of the system that in order to have a feeling that the system is useful for them so to ensure that we should consider usefulness while designing.

\subsection{Findable}

Find-ability is about making accessible the site by ensuring users can discover, find, or navigate to their desired content. Web sites have to be designed in a way that so users can easily find all they assume is present in a website.

\subsection{Credible}

Credibility has become an important topic because the web has becomes mostly used an information resource so user must trust and believe the contents of a Web site so the certain 
Design elements which can affect the believability of the source need to be considered.

\subsection{Accessible}

Accessibility is the ability to access and benefit from the system. Making the system accessible to users without restriction is very important in user experience. Web sites should be designed, developed and edited that all users have equal access to information. (Morville, 2011)

\subsection{Desirable}

Desirable means how the site affects to the users emotions and satisfying users. The emotion-al design which is image, brand must be considered not only the efficiency of the system.

Users find the usefulness, usability, and desirability of a Web application based on the sum of all earlier mentioned elements and their direct and indirect interactions with each other.

Usability and user experience are important in the overall success of a website as it relate to how well a product or service is designed. Usability is part of the user experience and plays a major role in experiences that are effective and pleasant. (Morville, 2011) Usability is about the user-friendliness and efficiency of the interface. Usability is a narrower concept than user experience since it only focuses on goal achievement. User experience takes a broader view in entire design; visual, interaction; information architecture and content strategy are also part of user experience as well as the thoughts and feelings from that interaction. Usability is one of those layers that influence the overall experience of ease of use. User experience includes usability but also addresses how a user feels when using a system. (Morville, 2011)

As it shown in figure 3.user experience involves a person's emotions about using a specific product, system or service.

User Experience includes the person experience, feeling, importan and valuable aspects of human- interaction. Additionally, it includes a person's perceptions of the practical aspects such as usefulness, ease of use and efficiency of the system. But usability is about making sure that something works well that a person of average ability and experience can use the website. (Krug, 2000)

\section{Experiment}

\subsection{Mobile application}

The main concern was to measure if the mobile users in the Jordanian culture would accept such approach of booking medical appointments with their doctors using a mobile application. To start, the mobile application was designed carefully in order to fulfil the needs of the users and support them with the process.

The first step was to design an Android application to address all of the user's aspects such as booking the appointment with the doctor The application was easy to use and self-explanatory as following: In this page, the user can effectively specify which doctor and major he/she can book an appointment with.

\subsection{Questionnaire}

The second phase was to investigate how far was the application accepted and addressed successfully all the needs of the user. In order to assure such, a 5 points likert scale 5 questions was formed to depict such approval. The survey was handled to over 300 participants and their answer was analysis as following.

Question One: It is important to have such systems in our daily life as it will make it easier.

Over $95 \%$ of the sample agreed and strongly did for such statement They explained that with the hefty life routine and the huge burden which falls on their shoulder, such application would safe loads of time and support them in a beneficial way.
Around $3 \%$ of the samples were neutral about such statement with reasons to declare.

A shy percentage of the sample (1\%) disagreed to such statement. They explained that life is already complicated and there is no need to add more complexity.

\subsection{Question 2}

When booking an appointment to visit the doctor, I often face problem to find a slot the suits me.

$77 \%$ of the sample agreed and strongly did, they explained that usually it is hard to find a time slot which can help them with their daily life routine and sometimes they might have to take the whole day off just to be able to visit the doctor on that day. In addition, they explained further that the most annoying thing happens when the doctor cancels his appointments on that day just out of the sudden. This will eventually mean that the patient must go through the process once again.

Less than $13 \%$ were neutral and kept aside for this question. They explained that it is a must to attend to the doctor's clinic to book an appointment and with such application it might work or simply might not.

$9 \%$ of the sample disagreed on such question. . They explained that if your arrived early to the clinic that will assure that you will get an appointment which fulfil your needs in term of time.

\subsection{Question three}

It's good to keep me posted with any changes that might happen to my scheduled appointment.

Over $90 \%$ of the sample agreed to the above statement. The explanations where vary, some of the participants explained that with today's busy life, it would be very difficult to get a second appointment in case the doctor cancelled the appointment due to life routine and work circumstances.

Moreover, it would be beneficial in case the doctor cancelled the appointment not to take the hassle of the journey to the doctor clinic and avoid such waste to time and money.

About $5 \%$ of the sample stood neutral, they didn't give a clear answer.

On the contrary, only $4 \%$ of the sample disagreed. They explained that it is always the doctor choice and it wouldn't make any difference.

\subsection{Question 4}

It is important to list the majority of the medical major's within the application.

Affirmatively, Over $98 \%$ of the sample strongly agreed on such question as it is mandatory to contain all of the majors. They added that such addition is crucial and excluding such would make it hard to use the application.

Only $1 \%$ was neutral, they explained that they will use whatever provided as majors and there is no need to list the whole majors.

Again, less than $1 \%$ of the sample disagreed; they didn't give an obvious reason.

\subsection{Question 5}

It is important to cover all of the geographical zones in Jordan: Over $84 \%$ of the sample agreed and strongly did for such question. They explained that it would be very beneficial to cover all of the areas in order to choose a doctor within the area which the patient lives in. they added that by this, the application will save them loads and loads of time and effort to reach to the proper choice.

Slightly over13percentage of the sample have chosen be stay neutral. They justified their choice by saying that whatever is available on the application, and then they might choose from. Additionally. 
They explained that the good doctors are most probably in the capital Amman and they will travel to them anyhow.

\subsection{Around $2 \%$}

Disagreed, they explained that each area is famous with some bright doctor names and what the reason of visiting the doctor was, and they would search for the names, which are more important.

\section{Conclusion}

The importance of UX rely on how easy applications and computer based systems would become. Thus, it is highly important to focus more on how to insure how usable and user friendly the application is instead of what functionality would it provide. In fact, we must combine both of the mentioned aspects together to achieve the UX dimension. The medical sector would get high befit of UX and its application. It was demonstrated how a mobile application would be highly beneficial for the users when it has more usability and functionality than just taking care of the design and so on. Users of the application were highly satisfied with the results which in its turn achieved high UX.

\section{Acknowledgment}

This research is funded by the Deanship of Research and Graduate Studies in Zarqa University /Jordan.

I would like to take the chance and thank Islam Al-Shanablah, RanaAl_jamal, Mansour Al-Atawenah and MayarGanem for their assistance in this work.

\section{References}

[1] Dumas, J. S. 1999. A Practical Guide to Usability Testing. Great Britain. Cromwell press.

[2] http://www.nngroup.com/articles/113-design-guidelineshomepage-usability/.

[3] http://www.nngroup.com/articles/usability-101-introductiontousability.

[4] Krug Steve 2005. Do not Make Me Think: A Common Sense Approach to Web Usability. Berkeley, CA. New Riders.

[5] Morville Peter 2011 The User Experience Honeycomb.

[6] http://www.melodiesinmarketing.com/2011/03/13/ux-user-experience-honeycomb design-aspects/.

[7] Nielsen Jacob and Marie Tahir, 2001 Homepage Usability.

[8] Nielsen, J. 2012. Usability 101: Introduction to Usability. New York. Nielsen Norman Group. Consulted.

[9] Nielson J. 1999. Designing Web Usability: The Practice of Simplicity. UK. New Riders.

[10] Nielson J. and Hoe Loranger 2006. Prioritizing Web Usability. Berkeley, CA. New Riders.

[11] Nielson J. and Pernice Kara 2009. Eye tracking Web Usability. Berkeley, CA. New Riders.

[12] Nielson. J. 1993. Usability Engineering. United Kingdom. Academic press Limited.

[13] Nielson. J. and Tahir Marie 2001. Homepage Usability: 50 Website.

[14] Preece. Jenny 1994. Human-computer interaction. England. Pearson Education Limited.

[15] Woldu, M., 2014 Evaluating Web Usability from the User's Perspective: a Laurea LIVE Intranet Case. 